\title{
The Efficacy of Mindfulness-Based Interventions in Primary Care: A Meta-Analytic Review
}

Marcelo M.P. Demarzo, PbD ${ }^{1}$

Jesús Montero-Marin, $\mathrm{PbD}^{2}$

Pim Cuijpers, $\mathrm{PbD}^{3}$

Edurne Zabaleta-del-Olmo, $\mathrm{PbD}^{4}$

Kamal R. Mabtani, $P b D^{5}$

Akke Vellinga, $P b D^{6}$

Caterina Vicens, $\mathrm{PbD}^{7}$

Yolanda López-del-Hoyo, $\mathrm{PbD}^{2}$

Javier García-Campayo, $P b D^{8}$

'Federal University of Sao Paulo

(UNIFESP), "Mente Aberta" - Brazilian

Center for Mindfulness and Health Promo-

tion, Department of Preventive Medicine,

Sao Paulo, Brazil

${ }^{2}$ Faculty of Health Sciences and Sports, University of Zaragoza, Huesca, Spain

${ }^{3}$ VU University Amsterdam, Department of Psychology, Amsterdam, Netherlands

${ }^{4}$ Institut Universitari d'Investigació en Atenció Primària (IDIAP) Jordi Gol, Barcelona, Spain

${ }^{5}$ Oxford University, Department of Primary Care, Oxford, United Kingdom

${ }^{6}$ National University of Ireland, Galway, Department of Primary Care, Galway, Ireland

${ }^{7}$ Red de Investigación en Actividades Preventivas y Promoción de la Salud (redIAPP), Primary Care, Palma de Mallorca, Spain

${ }^{8}$ University of Zaragoza, Department of Psychiatry, Zaragoza, Spain

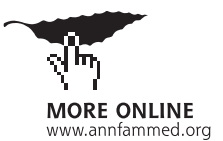

Conflicts of interest: authors report none.

\section{CORRESPONDING AUTHOR}

Javier García-Campayo, PhD Department of Psychiatry Miguel Servet University Hospital Avda Isabel La Católica I 50009 Zaragoza, Spain jgarcamp@gmail.com

\begin{abstract}
PURPOSE Positive effects have been reported after mindfulness-based interventions (MBIs) in diverse clinical and nonclinical populations. Primary care is a key health care setting for addressing common chronic conditions, and an effective $\mathrm{MBI}$ designed for this setting could benefit countless people worldwide. Metaanalyses of MBIs have become popular, but little is known about their efficacy in primary care. Our aim was to investigate the application and efficacy of MBls that address primary care patients.
\end{abstract}

METHODS We performed a meta-analytic review of randomized controlled trials addressing the effect of MBIs in adult patients recruited from primary care settings. The PRISMA (Preferred Reporting Items for Systematic Reviews and MetaAnalyses) and Cochrane guidelines were followed. Effect sizes were calculated with the Hedges $g$ in random effects models.

RESULTS The meta-analyses were based on 6 trials having a total of 553 patients. The overall effect size of $\mathrm{MBI}$ compared with a control condition for improving general health was moderate $(g=0.48 ; P=.002)$, with moderate heterogeneity $\left(I^{2}=59 ; P<.05\right)$. We found no indication of publication bias in the overall estimates. MBls were efficacious for improving mental health $(\mathrm{g}=0.56$; $P=.007)$, with a high heterogeneity $\left(1^{2}=78 ; P<.01\right)$, and for improving quality of life $(g=0.29 ; P=.002)$, with a low heterogeneity $\left(I^{2}=0 ; P>.05\right)$.

CONCLUSIONS Although the number of randomized controlled trials applying MBIs in primary care is still limited, our results suggest that these interventions are promising for the mental health and quality of life of primary care patients. We discuss innovative approaches for implementing MBIs, such as complex intervention and stepped care.

Ann Fam Med 2015;13:573-582. doi: 10.1370/afm.1863.

\section{INTRODUCTION}

$\mathrm{T}$ here is growing recognition of the value of mindfulness-based interventions (MBIs) for clinicians and policy makers. ${ }^{1.7}$ One important challenge for psychosocial intervention is to confirm the efficacy found in randomized controlled trials (RCTs) in routine clinical practice, particularly in primary care, ${ }^{8-10}$ where accessibility and adherence to and implementation of MBIs in health systems may be enhanced. ${ }^{11-13}$ MBIs are considered complex interventions because their implementation takes into account behavior change in patients and health professionals, as well as their adaptation to setting and culture. ${ }^{14}$

Our objective was to perform, for the first time, a meta-analytic review of RCTs to investigate the application and efficacy of MBIs in primary care patients. We had several initial hypotheses ${ }^{14}$ : (1) the number of welldesigned studies in primary care is greater than that in other levels of care, because most patients receive long-term assistance here ${ }_{i}(2)$ the clinical impact of MBIs in primary care patients is greater than that at other levels of the health system, because such patients adhere more to mindfulness programs $;$ (3) the range of health conditions addressed by MBIs is larger in primary care (including health promotion in at-risk population and 
application in patients with multimorbidity) ${ }_{1}^{15}$ owing to unrestricted access to such care; and (4) as MBIs are complex interventions in primary care, their program contents are systematically adapted to patients' local needs, services, culture, and epidemiology.

\section{METHODS}

We followed the PRISMA guidelines (Preferred Reporting Items for Systematic Reviews and MetaAnalyses) for systematic reviews and meta-analyses ${ }^{16}$ and the recommendations of the Cochrane Collaboration. ${ }^{17}$ The protocol was registered with PROSPERO (International Prospective Register of Systematic Reviews), registration number CRD42013004133.

\section{Eligibility Criteria}

We included RCTs of MBIs for patients recruited in primary care that compared the intervention with a control condition. Only RCTs were included to reduce bias, as mindfulness interventions have been criticized for their nonspecific components, such as their groupsupportive environment. ${ }^{18}$

We considered primary care services those that provide coordinated, accessible, comprehensive, and long-term health care services addressing a large majority of personal health care needs, and practices in the context of family and community. ${ }^{18}$ Only fulltext articles in peer-reviewed scientific journals were included. No restrictions were applied regarding language, control group characteristics, follow-up, or type of data analysis.

The RCTs had to take place among adult patients aged 18 years or older from primary care. No restrictions were placed on existing diseases or conditions, sex, race, or profession.

We allowed any MBI that listed mindfulness as a key component, including mindfulness-based stress reduction (MBSR), mindfulness-based cognitive therapy (MBCT), or similar. ${ }^{2}$ We excluded any blended or mixed intervention having only a mindfulness component, such as acceptance and commitment therapy (ACT) and dialectical behavioral therapy (DBT) or similar. The control condition could have included usual treatment, placement on a waiting list, or any active control, such as other types of psychosocial interventions, pharmacotherapy, or placebo.

The outcomes measured for this analysis were clinical outcomes and patientreported outcomes from any self-reported instrument used to measure mindfulness or any health-related variable (http://www. nihpromis.org/).

\section{Search Strategy}

We searched MEDLINE (via PubMed), Embase, PsycINFO, CINAHL (via EBSCO), LILACS, Scopus, and the Cochrane Central Register of Controlled Trials (CENTRAL). All searches were from database inception until September 4, 2014, where the medical subject heading $(\mathrm{MH})$ term mindfulness was included. We combined controlled vocabulary and free-text terms; Table 1 shows the general search strategy, and Supplemental Appendix 1, available at http://www. annfammed.org/content/13/6/573/supp1/DC1, shows the specific search strategies for each database. Search results were imported into an electronic bibliography after the removal of duplicate citations. We also screened references in the included studies, performed citation tracking, and contacted other experts in the field for additional studies.

\section{Data Extraction and Coding}

Two authors (M.M.P.D. and J.G-C.) screened citations for inclusion by examining the titles and abstracts. Disagreements were discussed with a third author (J.M-M.). Two reviewers (M.M.P.D. and J.G-C.) independently examined the full texts of the potentially relevant studies. Resolution for disagreement was reached through discussion with a third reviewer (J.M-M.). Each selected study was assessed independently by at least 2 authors (M.M.P.D., K.M., A.V., E.Z-O., Y.L-H., C.V., or J.G-C.), and the data were extracted using a predefined data extraction sheet. Any disagreement was referred to another author (J.M-M.) for resolution.

We coded the studies for year and country of publication $_{i}$ target patient and disorder or condition, age; percentage of women; MBI type and characteristics (number of sessions and length of intervention);

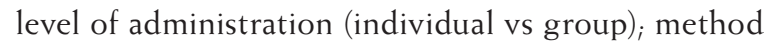
of administration (human vs media) ${ }_{i}$ type of control condition; number of participants; setting for delivery; role of the health professional delivering the intervention; follow-up; completion rate; primary and secondary outcomes; and added contact after intervention.

\section{Table 1. Search Strategy}

("Mindfulness"[MH] OR mindful*[tiab] OR Zen[tiab] OR Vipassana[tiab] OR acceptance-based[tiab] OR "commitment therapy"[tiab] OR DBT[tiab] OR MBSR[tiab] OR MBCT[tiab]) AND ("Primary Health Care"[MH] OR "Family Practice"[MH] OR "General Practice" [MH] OR "General Practitioners"[MH] OR "Physicians, Family"[MH] OR "Community Health Services"[MH] OR "Community Health Nursing"[MH] OR "Community Health Centers"[MH] OR "Community Medicine" [MH] OR "primary health care" OR "primary care" OR ((family OR general) AND (practi* OR physician*)) OR (community AND (medicine OR services OR nursing OR center* OR (enter*))).

Note: Shown is the complete search strategy for Medline, which was adapted for each database as necessary. 


\section{Assessment of Study Quality}

Risk of bias was assessed using the Cochrane Collaboration's tool ${ }_{1}^{19}$ considering those studies that met 3 or more criteria as high quality, and those that met fewer criteria as low quality. ${ }^{20}$ Quality of interventions was evaluated according to 3 criteria $^{21}$ : use of a treatment manual, provision of therapy by specifically trained therapists, and verification of treatment integrity during the study. Two reviewers (M.M.P.D. and J.M-M.) independently assessed these criteria, and any discrepancies were discussed with a third reviewer (J.G-C.) for consensus.

\section{Data Synthesis}

We calculated effect sizes, indicating the differences between the 2 groups and the 95\% confidence intervals at posttest or follow-up. ${ }^{22,23}$ When necessary, combined outcomes were estimated using a pooled mean-effect size provided by the Comprehensive Meta-Analysis-2.0 program (Biostat Inc). We chose the Hedges $g$ as the effect size measure because it adjusts accordingly for studies with a small sample size. ${ }^{24}$ It has been suggested that a $g$ value of 0.0 to 0.40 can be considered small $; 0.4-0.7$, moderate; and greater than 0.7 , large. ${ }^{17}$

Because considerable heterogeneity among studies was expected, the pooled effect size was calculated using the random effects model. We tested heterogeneity using the $\mathrm{I}^{2}$ statistic and $95 \%$ confidence intervals, ${ }^{25-28}$ assuming a value of $25 \%$ to indicate low heterogeneity; $50 \%$, moderate and $75 \%$, high. We also calculated the Q statistic and the associated $P$ value.

Subgroup analyses were conducted with the mixed effects model to evaluate possible differences according to the outcome (mental health or quality of life), type of intervention (MBSR or MBCT), time point of measurement (posttest, follow-up $<6$ months, follow-up $>6$ months), type of control condition (active or passive), type of clinical condition or disease (mental or somatic), use of intention-to-treat analysis (yes or no), study quality (high or low), and origin (Europe or rest of the world) as probable sources of heterogeneity. This model pools studies within the subgroups of the random-effects model and tests for significant differences between subgroups with the fixed-effects model. ${ }^{29} \mathrm{~W}$ hen subgroups had fewer than 3 trials, we did not analyze heterogeneity and risk of bias.

\section{Publication Bias}

We assessed publication bias through funnel plots. ${ }^{30-32}$ The test of Egger et $\mathrm{a}^{133}$ was used to contrast the null hypothesis with biased absences, and the trim and fill procedure of Duval and Tweedie ${ }^{32}$ provided the number of studies probably absent, allowing an estimate of the effect sizes taking publication bias into account. We also applied the rank correlation of Begg and Mazumdar ${ }^{34}$ to test whether the adjusted and observed effect sizes differed significantly.

All of the tests were 2 tailed, except for the biasrelated tests, which were 1 tailed. We used a significance level of $P<.05$.

\section{RESULTS}

We identified 4,440 records. Ultimately, 6 RCTs were included $^{4,35-39}$ (5 in English and 1 in Norwegian) representing a total of 553 participants (Figure 1). In the MBI group, 308 participants received the intervention

\section{Figure 1. Flow diagram of article selection.}

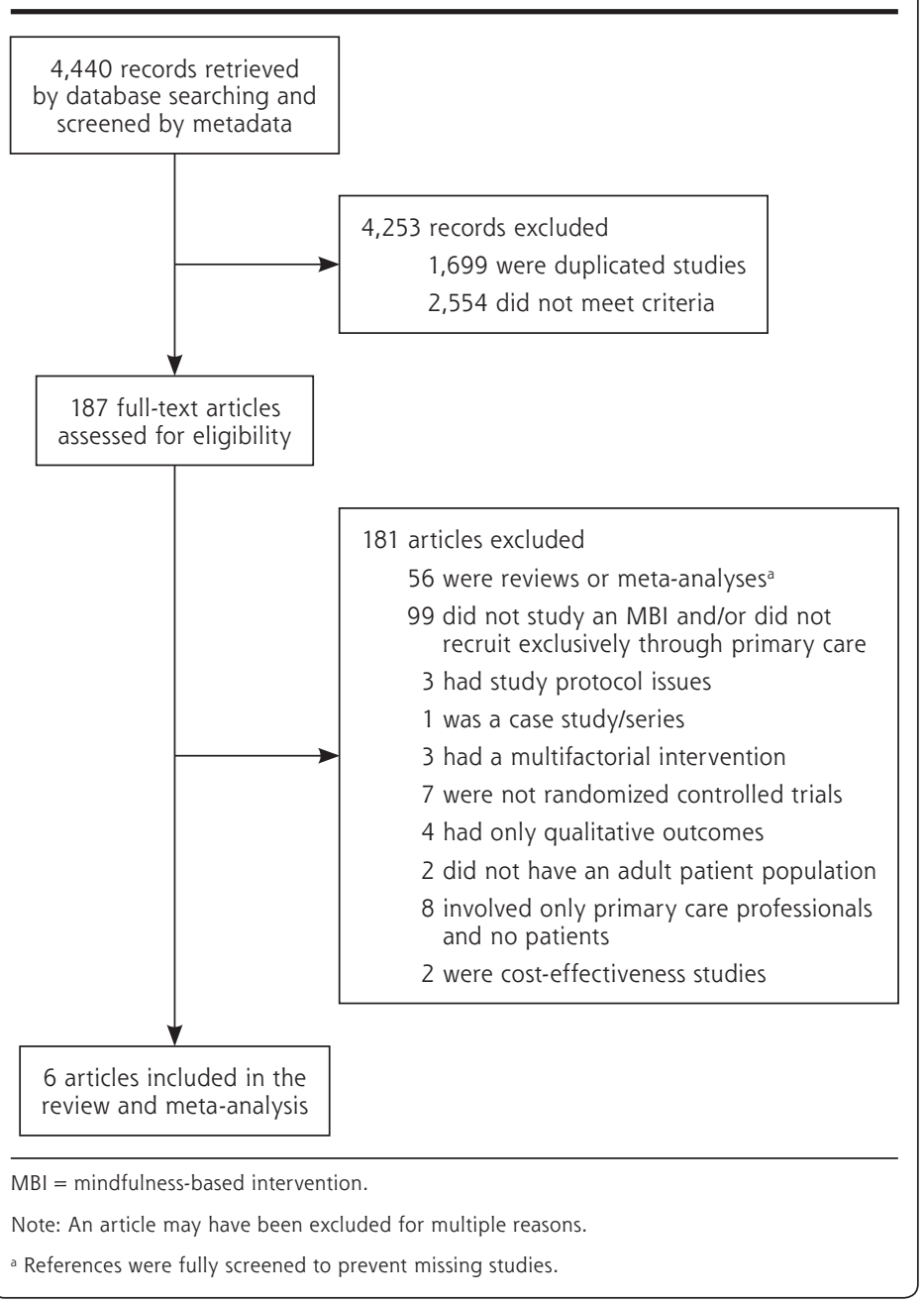


for depression, chronic pain, and medically unexplained symptoms.

\section{Characteristics of Included RCTs}

Table 2 shows the characteristics of the 6 included RCTs, 3 of which applied an MBSR-like program and 3 an MBCT-like program. All tested face-to-face group interventions and were published between 2005 and 2013. The mean age of participants ranged from 43.6 to 69.8 years, and their clinical conditions included chronic musculoskeletal pain, mood disturbance, chronic stress, chronic illness, and medically unexplained symptoms.

\section{Table 2. Characteristics of the Included Trials}

\begin{tabular}{|c|c|c|c|c|c|}
\hline $\begin{array}{l}\text { Trial, Year, } \\
\text { Country }\end{array}$ & Population & $\begin{array}{l}\text { Age, Mean (SD) } \\
\text { or (IQR), y }\end{array}$ & $\begin{array}{l}\text { Female, } \\
\%\end{array}$ & Intervention & Control \\
\hline $\begin{array}{l}\text { Plews-Ogan et } \mathrm{al}^{37} \\
2005 \\
\text { United States }\end{array}$ & $\begin{array}{l}\text { Patients with chronic } \\
\text { musculoskeletal pain }\end{array}$ & $\begin{array}{l}\text { All groups: } 46.5 \\
\text { (SD not given) }\end{array}$ & 76.7 & $\begin{array}{l}\text { MBSR } \\
8 \text { weeks } \\
2.5 \text { hours/week } \\
\text { Face to face and audio }(n=10)\end{array}$ & $\begin{array}{l}\text { Usual care }(P C) \\
\qquad(n=10) \\
\text { Massage }(A C) \\
\quad(n=10)\end{array}$ \\
\hline $\begin{array}{l}\text { Moritz et } \mathrm{al}^{36} \\
2006 \\
\text { Canada }\end{array}$ & $\begin{array}{l}\text { Patients with mood } \\
\text { disturbance ( } \geq 40 \text { on } \\
\text { POMS) }\end{array}$ & $\begin{array}{l}\text { I: } 43.6 \\
P C: 43.9 \\
\text { AC: } 44.6 \text { (SDs not } \\
\text { given) }\end{array}$ & 83.6 & $\begin{array}{l}\text { MBSR }^{b} \\
8 \text { weeks } \\
1.5 \text { hours/week } \\
\text { Face to face and audio }(n=54)\end{array}$ & $\begin{array}{l}\text { Wait list }(P C)(n=55) \\
\text { Spirituality program } \\
(A C)(n=56)\end{array}$ \\
\hline $\begin{array}{l}\text { de Vibe and } \\
\text { Moum }{ }^{39} \\
2006 \\
\text { Norway }\end{array}$ & $\begin{array}{l}\text { Patients with stress } \\
\text { and chronic illness }\end{array}$ & $\begin{array}{l}\text { I: } 47(20-69) \\
P C: 48(17-63)\end{array}$ & 88.0 & $\begin{array}{l}\text { MBSR } \\
8 \text { weeks } \\
2.5 \text { hours/week } \\
\text { Face to face and audio }(n=102)\end{array}$ & Wait list $(P C)(n=42)$ \\
\hline $\begin{array}{l}\text { Kuyken et } \mathrm{al}^{4} \\
2008 \\
\text { United Kingdom }\end{array}$ & $\begin{array}{l}\text { Patient with recurrent } \\
\text { depression ( } \geq 3 \text { pre- } \\
\text { vious episodes) }\end{array}$ & $\begin{array}{l}\text { I: } 48.95(10.55) \\
A C: 49.37(11.84)\end{array}$ & 47.0 & $\begin{array}{l}\text { MBCT } \\
8 \text { weeks } \\
2 \text { hours/week } \\
\text { Face to face }(n=61)\end{array}$ & $\begin{array}{l}\text { Usual care }(A C) \\
\qquad(n=62)\end{array}$ \\
\hline $\begin{array}{l}\text { Kitsumban et } \mathrm{al}^{38} \\
2009 \\
\text { Thailand }\end{array}$ & $\begin{array}{l}\text { Elderly women with } \\
\text { depression }\end{array}$ & $\begin{array}{l}\text { I: } 69.81(60-80) \\
P C: 68.70(60-80)\end{array}$ & 100 & $\begin{array}{l}\text { CMPPd } \\
4 \text { weeks/11 sessions } \\
5 \text { six-hour sessions of mindful- } \\
\text { ness }+6 \text { three-hour sessions of CT } \\
\text { Face to face }(n=30)\end{array}$ & $\begin{array}{l}\text { Usual care }(P C) \\
\quad(n=30)\end{array}$ \\
\hline $\begin{array}{l}\text { Van Ravesteijn } \\
\text { et al }{ }^{35} \\
2013 \\
\text { Netherlands }\end{array}$ & $\begin{array}{l}\text { Patients with medi- } \\
\text { cally unexplained } \\
\text { symptoms }\end{array}$ & $\begin{array}{l}\text { I: } 47.0(13.3) \\
\text { AC: } 48.1(12.3)\end{array}$ & 75.2 & $\begin{array}{l}\text { МBCT } \\
8 \text { weeks } \\
2.5 \text { hours/week } \\
\text { Face to face and audio }(n=64)\end{array}$ & $\begin{array}{l}\text { Usual care }(P C) \\
\qquad(n=61)\end{array}$ \\
\hline
\end{tabular}

$\mathrm{AC}=$ active control; $\mathrm{AS}=$ adequate generation of allocation sequence; $\mathrm{BDI}=$ Beck Depression Inventory; $\mathrm{CA}=$ concealment of allocation; $\mathrm{CINIM}=\mathrm{Canadian}$ Institute of Natural and Integrative Medicine; CMPP = cognitive-mindfulness practice program; $C T=$ cognitive therapy; GP = general practitioner; $I=$ intervention; $I O=$ dealing with incomplete outcome data; IQR = interquartile range; $\mathrm{MBCT}=$ mindfulness-based cognitive therapy; $\mathrm{MBSR}=$ mindfulness-based stress reduction; $\mathrm{PC}=$ passive control; PHQ-9 = 9-item Patient Health Questionnaire; PHQ-15 = 15-item Patient Health Questionnaire; PK = prevention of knowledge of the allocated intervention; POMS = Profile of Mood States; QoL = quality of life; SF-12 = Medical Outcomes Study 12-item Short Form Health Survey; SF-36= Medical Outcomes Study 36 -item Short Form Health Survey; VAS = visual analogue scale; WHOQOL-BREF = 26-item World Health Organization Quality of Life scale. 
Most of the trials used 8 sessions, with 1 session each week lasting an average of 2 hours. The control conditions used were wait lists, usual care, and massage or spirituality programs. Measures were collected from posttest to 15 months after intervention, and all outcomes were related to mental health or quality of life.

\section{Quality of Included RCTs}

Two RCTs were considered high quality, and 4 were considered low quality (Table 2). ${ }^{19}$ Regarding the quality of the interventions, the use of a treatment manual was reported in all trials, therapist training in 3 trials, and treatment integrity in 1 trial. One trial met all

\begin{tabular}{|c|c|c|c|c|c|c|}
\hline Setting & $\begin{array}{l}\text { Professional/ } \\
\text { Therapist }\end{array}$ & $\begin{array}{l}\text { Time } \\
\text { Points }\end{array}$ & $\begin{array}{l}\text { Completion } \\
\text { Rate, \% }{ }^{a}\end{array}$ & Outcomes & $\begin{array}{l}\text { Trial } \\
\text { Qualityc }\end{array}$ & $\begin{array}{l}\text { Intervention } \\
\text { Quality }\end{array}$ \\
\hline Not given & $\begin{array}{l}\text { Training and experi- } \\
\text { ence not given }\end{array}$ & $\begin{array}{l}\text { Posttest } \\
4 \text { weeks }\end{array}$ & $\begin{array}{l}\text { I: } 50.0 \\
P C: 80.0 \\
A C: 90.0\end{array}$ & $\begin{array}{l}\text { VAS pain and unpleasantness } \\
\text { SF-12 global mental health }\end{array}$ & $\begin{array}{l}\text { AS (+) } \\
\text { CA (-) } \\
\text { PK (-) } \\
\text { IO (-) }\end{array}$ & $\begin{array}{l}\text { Manual (+) } \\
\text { Training (-) } \\
\text { Integrity check (-) }\end{array}$ \\
\hline CINIM & $\begin{array}{l}\text { Not given for MBSR; } \\
\text { experienced psy- } \\
\text { chiatrist for spiritu- } \\
\text { ality program }\end{array}$ & $\begin{array}{l}\text { Posttest } \\
4 \text { weeks }\end{array}$ & $\begin{array}{l}\text { I: } 76.0 \\
P C: 96.0 \\
\text { AC: } 75.0\end{array}$ & $\begin{array}{l}\text { POMS } \\
\text { SF-36 Mental Health } \\
\text { SF-36 Physical Health }\end{array}$ & $\begin{array}{l}\mathrm{AS}(+) \\
\mathrm{CA}(+) \\
\mathrm{PK}(-) \\
\mathrm{IO}(-)\end{array}$ & $\begin{array}{l}\text { Manual (+) } \\
\text { Training (-) } \\
\text { Integrity check (-) }\end{array}$ \\
\hline Not given & $\begin{array}{l}\text { GPs; training and } \\
\text { experience not } \\
\text { given }\end{array}$ & Posttest & 92.0 & $\begin{array}{l}\text { WHOQOL-BREF Global QoL } \\
\text { WHOQOL-BREF Global Health } \\
\text { WHOQOL-BREF Physical Health } \\
\text { WHOQOL-BREF Mental Health } \\
\text { WHOQOL-BREF Social Health } \\
\text { WHOQOL-BREF Environmental Health } \\
\text { Subjective Health Complaint } \\
\text { Hopkins Symptom Checklist }\end{array}$ & $\begin{array}{l}\text { AS (-) } \\
\text { CA (-) } \\
\text { PK (-) } \\
\text { IO (-) }\end{array}$ & $\begin{array}{l}\text { Manual }(+) \\
\text { Training }(-) \\
\text { Integrity check }(-)\end{array}$ \\
\hline $\begin{array}{l}\text { Primary care; } \\
\text { group ( } 9-15 \\
\text { patients) }\end{array}$ & $\begin{array}{l}\text { MBCT therapists: } \\
\text { training program } \\
\text { taught and super- } \\
\text { vised by a devel- } \\
\text { oper of MBCT }\end{array}$ & $\begin{array}{l}\text { Posttest } \\
15 \text { months }\end{array}$ & $\begin{array}{l}\text { I: } 85.0 \\
\text { AC: } 84.0\end{array}$ & $\begin{array}{l}\text { Recurrence } \\
\text { Depression } \\
\text { BDI-II } \\
\text { Hamilton Rating Scale for } \\
\quad \text { Depression } \\
\text { WHOQOL-BREF Physical Health } \\
\text { WHOQOL-BREF Mental Health } \\
\text { WHOQOL-BREF Social Health } \\
\text { WHOQOL-BREF Physical Health }\end{array}$ & $\begin{array}{l}\mathrm{AS}(+) \\
\mathrm{CA}(+) \\
\mathrm{PK}(+) \\
\mathrm{IO}(+)\end{array}$ & $\begin{array}{l}\text { Manual (+) } \\
\text { Training (+) } \\
\text { Integrity check (+) }\end{array}$ \\
\hline $\begin{array}{l}\text { Not given; } \\
\text { group (7-14 } \\
\text { patients) }\end{array}$ & $\begin{array}{l}\text { Certified and experi- } \\
\text { enced mindfulness } \\
\text { teachers }\end{array}$ & $\begin{array}{l}\text { Posttest } \\
9 \text { months }\end{array}$ & $\begin{array}{l}\text { I: } 76.0 \\
\text { PC: } 90.0\end{array}$ & $\begin{array}{l}\text { SF-36 Mental Health } \\
\text { SF-36 Physical Health } \\
\text { General Health Status VAS } \\
\text { PHQ-15 Physical symptoms } \\
\text { PHQ-9 Depressive symptoms } \\
\text { Nonreactivity } \\
\text { Five-Facet Mindfulness } \\
\text { 14-item Whitely Index Anxiety } \\
\text { Observing Five-Facet Mindfulness } \\
\text { Describing Five-Facet Mindfulness } \\
\text { Acting Five-Facet Mindfulness } \\
\text { Nonjudging Five-Facet Mindfulness }\end{array}$ & $\begin{array}{l}\mathrm{AS}(+) \\
\mathrm{CA}(+) \\
\mathrm{PK}(+) \\
\mathrm{IO}(+)\end{array}$ & $\begin{array}{l}\text { Manual (+) } \\
\text { Training (+) } \\
\text { Integrity check (-) }\end{array}$ \\
\hline
\end{tabular}

${ }^{a}$ Adequate completion dose was defined as participation in 4 or more sessions. ${ }^{4}$

${ }^{b}$ MBSR was considered a control group in the original study.

' Risk of bias: low (+), high (-), or unclear (?). ${ }^{19}$

$\mathrm{d}$ Considered as MBCT-like in the meta-analysis. 
criteria, 2 met 2 criteria, and 3 met 1 criterion for the quality of interventions. ${ }^{21}$

\section{Outcomes}

MBI was efficacious for improving general health $(\mathrm{g}=0.48)$, with moderate heterogeneity $\left(\mathrm{I}^{2}=59 ; \mathrm{P}\right.$ $<.05$ ) (Figure 2 and Table 3). We found no indication of publication bias (Appendix 2, available at http:// www.annfammed.org/content/13/6/312/suppl/DC1). MBI was also efficacious for improving mental health $(\mathrm{g}=0.56)$, with a high heterogeneity $\left(\mathrm{I}^{2}=78_{i} P<.01\right)$, and for improving quality of life $(g=0.29)$, with a low heterogeneity $\left(\mathrm{I}^{2}=0 ; \mathrm{P}>.05\right)$. After adjusting for publication bias (only 1 trial was imputed studies), the effect size for mental health outcomes declined slightly $(g=0.41)$. We identified no publication bias for quality of life.

We did not find any differences by outcome or intervention, but we did find differences according to the time point of outcome measurement (follow-up of less than 6 months had the greatest effect size, followed by posttest time point and follow-up of greater than 6 months) and type of control (effect size was much greater when MBI was compared with a passive control than with an active control). Heterogeneity was high for 4 characteristics: MBCT, active controls, passive controls, and mental disease. The test of Egger et $\mathrm{al}^{33}$ was significant, with a high risk of publication bias, for MBCT, follow-up of less than 6 months, and use of intention-to-treat analysis, whereas the test of Begg and Mazumdar ${ }^{34}$ was not significant for any fac- tors. After adjustment, the effect size increased for the posttest time point, active controls, passive controls, and high risk of bias. We did not conduct any subgroup analyses based on the quality of interventions because of the small number of trials.

\section{DISCUSSION}

\section{Findings in Context}

We found 6 RCTs of MBIs conducted in primary care, which is low compared with the number conducted in secondary or tertiary care. ${ }^{2,3}$ This disparity may be due to the fact that research in primary care is still comparatively less developed. ${ }^{40}$

Our analysis showed a moderate effect size in favor of MBIs in primary care for mental health-related outcomes and quality of life, with a low risk of publication bias and a moderate level of heterogeneity. This effect size is similar to that observed across general clinical populations and other settings. ${ }^{2}$ Primary care could enhance compliance with and adherence to practice and improve the impact of these interventions, ${ }^{14}$ although this was not evident in our findings. We did not observe evidence that MBIs were explicitly adapted for primary care patients, which may explain lack of relatively greater benefit in this setting. ${ }^{41}$

Furthermore, the effect sizes for MBIs were similar to those found for pharmacologic and psychological therapies in primary care for such complex disorders as fibromyalgia. ${ }^{13}$ In subgroup analyses, we observed a large effect size when comparing MBIs with pas-

Figure 2. Forest plot for the effect size of mindfulness-based intervention on outcomes overall, and for mental health and quality of life outcomes individually.

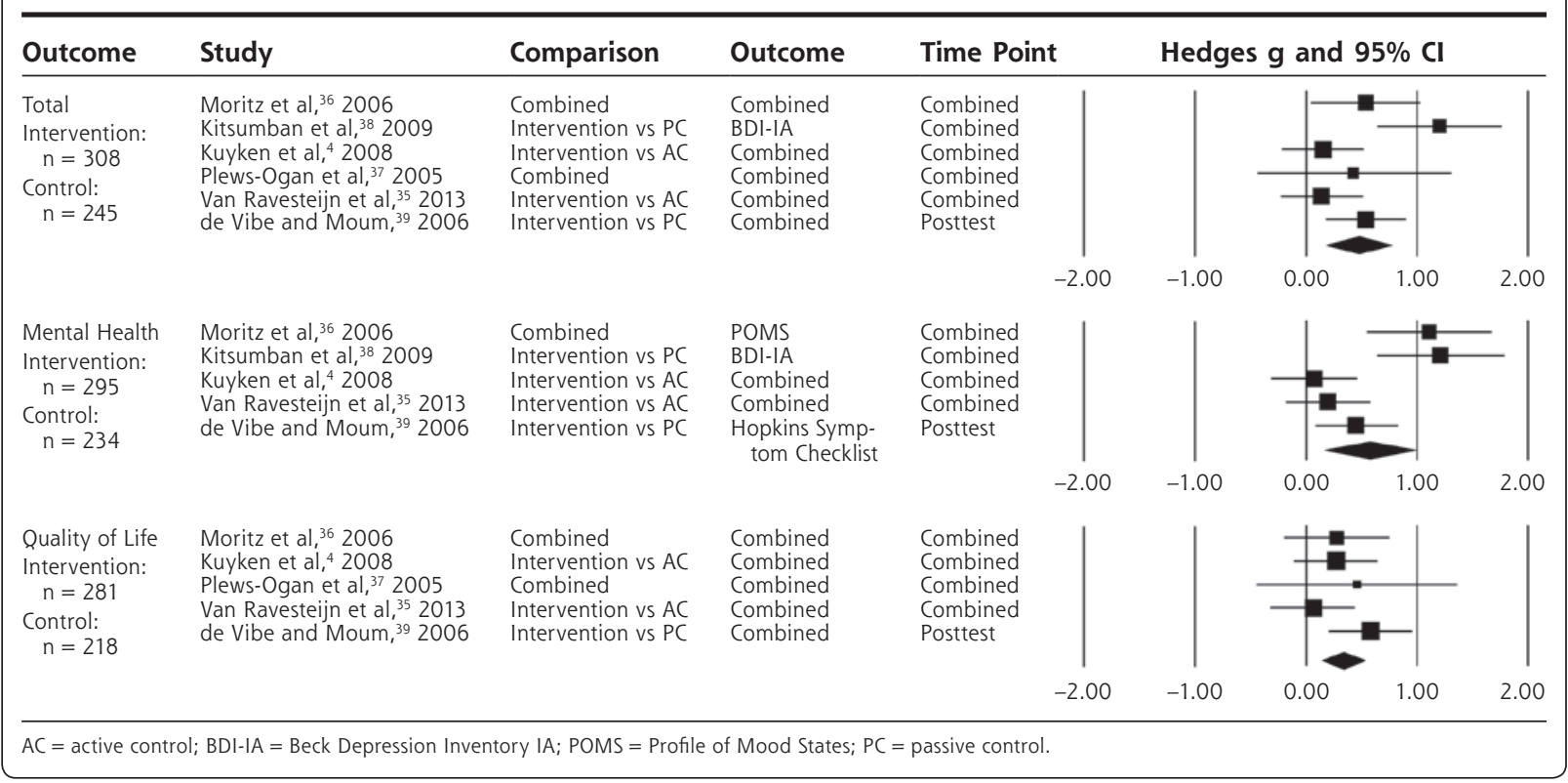


Table 3. Combined Effect Sizes and Heterogeneity

\begin{tabular}{|c|c|c|c|c|}
\hline $\begin{array}{l}\text { Characteristic } \\
\text { (Number of Trials) }\end{array}$ & $\begin{array}{l}\text { Effect Size, } \\
\text { g }(95 \% \mathrm{Cl})\end{array}$ & $\begin{array}{c}P \\
\text { Value }^{a}\end{array}$ & $\begin{array}{l}\text { Heterogeneity, } \\
I^{2}(95 \% \mathrm{Cl})\end{array}$ & $\begin{array}{c}P \\
\text { Value }^{b}\end{array}$ \\
\hline Total (6) & $0.48(0.18$ to 0.77$)$ & .002 & $59^{c}(0$ to 83$)$ & \\
\hline \multicolumn{5}{|l|}{ Outcome } \\
\hline Mental health (5) & $0.56(0.15$ to 0.97$)$ & .007 & $78^{\mathrm{d}}$ (46 to 91 ) & \multirow[t]{2}{*}{.24} \\
\hline Quality of life (5) & $0.29(0.11$ to 0.48$)$ & .002 & 0 (0 to 79$)$ & \\
\hline \multicolumn{5}{|l|}{ Intervention } \\
\hline MBSR (3) & $0.53(0.26$ to 0.81$)$ & $<.001$ & 0 (0 to 90$)$ & \multirow[t]{2}{*}{.84} \\
\hline $\operatorname{MBCT}(3)$ & $0.47(-0.11$ to 1.05$)$ & .12 & $82^{d}$ (45 to 94$)$ & \\
\hline \multicolumn{5}{|l|}{ Time point } \\
\hline Posttest (6) & $0.45(0.15$ to 0.75$)$ & .004 & $62^{c}$ (7 to 89) & \multirow[t]{3}{*}{.02} \\
\hline Follow-up $<6$ months (3) & $1.08(0.73$ to 1.43$)$ & $<.001$ & $0(0$ to 90$)$ & \\
\hline Follow-up >6 months (2) & $0.13(-0.14$ to 0.39$)$ & .35 & $0(-)$ & \\
\hline \multicolumn{5}{|l|}{ Comparison } \\
\hline Active control (4) & $-0.22(-0.92$ to 0.48$)$ & .55 & $89^{e}$ (75 to 95$)$ & \multirow[t]{2}{*}{.01} \\
\hline Passive control (4) & $1.22(0.36$ to 2.07$)$ & .005 & $90^{e}$ (77 to 96$)$ & \\
\hline \multicolumn{5}{|l|}{ Disease } \\
\hline Mental (3) & $0.62(0.02$ to 1.20$)$ & .04 & $79^{d}$ (32 to 93) & \multirow[t]{2}{*}{.44} \\
\hline Somatic (3) & $0.36(0.08$ to 0.63$)$ & .01 & $13(0$ to 91$)$ & \\
\hline \multicolumn{5}{|l|}{ Intention-to-treat analysis } \\
\hline No (3) & $0.75(0.27$ to 1.22$)$ & .002 & $53(0$ to 86$)$ & \multirow[t]{2}{*}{.059} \\
\hline Yes (3) & $0.24(0.01$ to 0.47$)$ & .04 & 0 (0 to 90$)$ & \\
\hline \multicolumn{5}{|l|}{ Study quality } \\
\hline High (2) & $0.15(-0.11$ to 0.41$)$ & .25 & $0(-)$ & \multirow[t]{2}{*}{.01} \\
\hline Low (4) & $0.68(0.36$ to 1.01$)$ & $<.001$ & $34(0$ to 77$)$ & \\
\hline \multicolumn{5}{|l|}{ World region } \\
\hline Europe (3) & $0.29(0.03$ to 0.54$)$ & .03 & 31 (0 to 93$)$ & \multirow[t]{2}{*}{.08} \\
\hline Rest of the world (3) & $0.77(0.28$ to 1.25$)$ & .002 & $46(0$ to 89$)$ & \\
\hline \multicolumn{5}{|c|}{$\mathrm{MBCT}=$ mindfulness-based cognitive therapy; $\mathrm{MBSR}=$ mindfulness-based stress reduction. } \\
\hline \multicolumn{5}{|c|}{$\begin{array}{l}\text { Notes: The } g \text { value is the Hedges effect size. The } 1^{2} \text { value is the proportion of real observed dispersion (not cal- } \\
\text { culated for cells having a sample size of fewer than } 3 \text { trials). }\end{array}$} \\
\hline \multicolumn{5}{|c|}{ a The $P$ value associated with the effect size. } \\
\hline \multicolumn{5}{|c|}{${ }^{b}$ The $P$ value associated with the mixed effects contrast. } \\
\hline \multicolumn{5}{|c|}{$c P<.05$} \\
\hline \multicolumn{5}{|l|}{$\mathrm{d} P<.01$} \\
\hline e $P<.001$ & & & & \\
\hline
\end{tabular}

When comparing the effect of MBI between end of the intervention and follow-ups longer than 6 months, the impact tended to decrease. Interestingly, the effect was greater at a follow-up of less than 6 months than at intervention end, however, this finding may be explained by the passive control used in these studies. In addition, we observed that the MBSR and MBCT models had similar effects (moderate), which supports the hypothesis that MBSR is no different from any other psychotherapeutic intervention. Heterogeneity, however, was significant and much larger than that for MBCT. On the other hand, benefit was greater for mental health outcomes than for quality of life outcomes, although the difference was not significant and heterogeneity was high when it came to mental health outcome, probably because of the different methods used to measure it. Similarly, although the difference was not significant, the impact of MBIs on mental disorders was larger than that on somatic conditions, which could be expected based on previous meta-analyses. ${ }^{2,43}$

The range of health conditions addressed by MBIs was

sive control conditions, but not when comparing them with active control conditions. Previous metaanalyses have shown similar results. ${ }^{2,35,42}$ Khoury et al ${ }^{2}$ observed a moderate effect size when comparing MBIs with wait list controls, but this effect was small when compared with active controls, and even smaller when including psychotherapy. The authors concluded that MBIs did not differ from cognitive behavior therapies or pharmacotherapy. ${ }^{2}$ In a meta-analysis of RCTs addressing the efficacy of MBIs against an active control group, Goyal et $\mathrm{al}^{3}$ found small effect sizes for improvements in anxiety, depression, and pain, which were similar to the effects of other active treatments such as cognitive behavior therapy, exercise, other behavioral therapies, or drugs. ${ }^{3}$ Small or moderate effect sizes for psychosocial interventions similar to pharmacotherapies were expected. ${ }^{43}$ large, but because of the limited number of studies, we were unable to compare efficacy with that in other levels of health care. MBIs have still not been tested among patients with multimorbidity, even though this population may be a potential target for these interventions. ${ }^{15}$

Most of the RCTs were classified as being of poor quality (only 2 had a high-quality score), and those with higher quality had a smaller effect size. An intention-to-treat analysis decreased the effect size, although the difference was not significant. Most of the interventions themselves were rated as having a low level of quality, although the importance of strictly following the treatment manual and integrity may be less strict in primary care implementation, and regarding complex interventions such as MBIs. Moreover, information about patient safety, regarding any unin- 
tended or adverse effect related to the interventions, has not been reported, although it is not clear whether these potential effects were presented or systematically addressed in the reviewed studies. ${ }^{44-46}$

Because MBIs have self-efficacy components that support life-long skills, such as self-awareness, emotional self-regulation, less worry and rumination, and meta-cognition, ${ }^{47}$ these interventions may have more sustainable effects on health in the long term, as shown in recent studies ${ }^{48}$ Given limited long-term follow-up studies, the results from this and other reviews remain inconclusive, ${ }^{2,42,49}$ even though MBIs seem to maintain at least some of their effect size over time. ${ }^{3}$ Another key question is whether MBIs are cost-effective, and the preliminary results are promising. ${ }^{4,5}$

In the trials included in this meta-analysis, the contents of MBI programs were not adapted to primary care patients' local needs, culture, or epidemiology; thus, future protocols should include this framework. Another key component when implementing primary care interventions is the stepped-care approach, ${ }^{14,50}$ but none of the trials addressed this issue, probably because of the uniformly strict adherence to the manual for MBI programs. On the other hand, when considering the implementation of complex interventions in primary care, professionals and researchers should be more flexible in adapting protocols to the context of this setting within the health system, for example, by using shorter protocols or self-help online interventions. ${ }^{51}$ Further studies should address this essential point $_{i}$ indeed, many are already including some of these issues, such as the ongoing PREVENT study (Mindfulness-Based Cognitive Therapy Compared With Maintenance Antidepressant Treatment in the Prevention of Depressive Relapse or Recurrence). ${ }^{52}$

\section{Limitations}

We did not include pediatric patients in our analysis, despite the potentially beneficial application of MBIs to this population, ${ }^{53,54}$ because primary care in many countries does not include children younger than 14 years of age.

Moreover, the number of RCTs applying MBIs in primary care patients is still limited, and our conclusions should be interpreted with caution because of the lack of statistical power. In addition, the overall quality of the included studies was generally low, as they were based on different comparators and outcomes, and had insufficient follow-up time points. Most of the patients were women; although expected in mind-body interventions, this unbalanced sex distribution may bias results. We found moderate levels of heterogeneity among trials, and they remained substantial after pointing out possible sources of vari- ance, stratifying with the mixed effects model, and using combined outcomes with a pooled mean. As we have seen, the outcomes assessed respond to a wide variety of symptoms, from mental health to quality of life $_{i}$ however, heterogeneity seems to be concentrated in mental health outcomes. This pattern could be due to the different instruments used across trials. On the other hand, the comparisons with both active and passive controls showed significant differences between them, with high heterogeneity; therefore, another important part of heterogeneity could respond to differences in comparison groups according to the control used, as shown in previous studies. ${ }^{2}$

\section{Implications for Practice}

This meta-analysis is the first to address the efficacy of MBIs in primary care patients. There is still insufficient evidence to draw a conclusion about the effects of mindfulness interventions in this setting, and well-designed RCTs and translational studies in this context are needed. Our results, however, suggest that these psychosocial complex interventions are promising for this particular clinical population and level of care. Several questions remain unanswered, and future research protocols addressing the implementation of MBIs in primary care are greatly needed. Some recommendations, such as addressing MBIs as complex interventions, considering a stepped-care model, and evaluating adaptation of these interventions to the needs and culture of patients and primary care services and their implementation process could affect outcomes and should be tested in further studies. The use of active and similar comparators, the evaluation of the long-term cost-effectiveness of these programs, and a systematic search for potential adverse effects of MBIs also seem to be necessary, to refine these results and to generate more robust evidence on the impact of MBIs in primary care and the health system.

To read or post commentaries in response to this article, see it online at http://www.annfammed.org/content/13/6/573.

Key words: mindfulness-based interventions; primary care; meta-analysis; randomized controlled trials; complex interventions; practice-base research

Submitted November 28, 2014; submitted, revised, June 19, 2015; accepted July 16, 2015.

Acknowledgments: Dr Demarzo is grateful to the CNPq - Brazilian National Council for Research and Technology Development for his postdoctoral fellowship (Science Without Borders Programme). The authors are grateful to Dr Svein Gjelstad for his translation of the article from Norwegian.

Supplementary materials: Available at http://www.AnnFamMed. org/content/13/6/573/suppl/DC1/. 


\section{References}

1. Cullen M. Mindfulness-based interventions: an emerging phenomenon. Mindfulness. 2011;2(3):186-193.

2. Khoury B, Lecomte T, Fortin G, et al. Mindfulness-based therapy: a comprehensive meta-analysis. Clin Psychol Rev. 2013;33(6):763-771.

3. Goyal M, Singh S, Sibinga EMS, et al. Meditation programs for psychological stress and well-being: a systematic review and metaanalysis. JAMA Intern Med. 2014;174(3):357-368.

4. Kuyken W, Byford S, Taylor RS, et al. Mindfulness-based cognitive therapy to prevent relapse in recurrent depression. J Consult Clin Psychol. 2008;76(6):966-978.

5. van Ravesteijn H, Grutters J, olde Hartman T, et al. Mindfulnessbased cognitive therapy for patients with medically unexplained symptoms: a cost-effectiveness study. J Psychosom Res. 2013;74(3): 197-205.

6. Kurdyak P, Newman A, Segal Z. Impact of mindfulness-based cognitive therapy on health care utilization: a population-based controlled comparison. J Psychosom Res. 2014;77(2):85-89.

7. Hempel S, Taylor S, Marshall N, et al. Evidence Map of Mindfulness. Washington, DC: US Department of Veterans Affairs; 2014.

8. Crane RS, Kuyken W. The implementation of mindfulness-based cognitive therapy: learning from the UK health service experience. Mindfulness (N Y). 2013:4:246-254.

9. Finucane A, Mercer SW. An exploratory mixed methods study of the acceptability and effectiveness mindfulness-based cognitive therapy for patients with active depression and anxiety in primary care. BMC Psychiatry. 2006;6:14.

10. De Maeseneer J, Roberts RG, Demarzo M, et al. Tackling NCDs: a different approach is needed. Lancet. 2012;379(9829):1860-1861.

11. García Campayo J. [The practice of "being attentive" (mindfulness) in medicine. Impact on patients and professionals]. Aten Primaria. 2008:40(7):363-366.

12. Demarzo MMP. [Meditation applied to health]. In: [Updating Program in Family and Community Medicine]. 6th ed. Porto Alegre, Brazil: Artmed Panamericana; 2011:1-18.

13. Garcia-Campayo J, Magdalena J, Magallón R, Fernández-García $E$, Salas $M$, Andrés E. A meta-analysis of the efficacy of fibromyalgia treatment according to level of care. Arthritis Res Ther. 2008; 10(4):R81.

14. Demarzo MM, Cebolla A, Garcia-Campayo J. The implementation of mindfulness in healthcare systems: a theoretical analysis. Gen Hosp Psychiatry. 2015;37(2):166-171.

15. Yardley S, Cottrell E, Rees E, Protheroe J. Modelling successful primary care for multimorbidity: a realist synthesis of successes and failures in concurrent learning and healthcare delivery. BMC Fam Pract. 2015;16:23.

16. Moher D, Liberati A, Tetzlaff J, Altman DG; PRISMA Group. Preferred reporting items for systematic reviews and meta-analyses: the PRISMA statement. Int J Surg. 2010;8(5):336-341.

17. Higgins JPT, Green S. Cochrane Handbook for Systematic Reviews of Interventions. Version 5.1.0. http://handbook.cochrane.org/. Updated March 2011. Accessed Apr 14, 2015.

18. Guyatt GH, Oxman AD, Vist GE, et al. GRADE: an emerging consensus on rating quality of evidence and strength of recommendations. BMJ. 2008;336(7650):924-926.

19. Higgins JPT, Altman DG, Gøtzsche PC, et al; Cochrane Bias Methods Group; Cochrane Statistical Methods Group. The Cochrane Collaboration's tool for assessing risk of bias in randomised trials. BMJ. 2011; 343:d5928.

20. Cuijpers P, Sijbrandij M, Koole S, Huibers M, Berking M, Andersson G. Psychological treatment of generalized anxiety disorder: a metaanalysis. Clin Psychol Rev. 2014;34(2):130-140.
21. Chambless DL, Hollon SD. Defining empirically supported therapies. J Consult Clin Psychol. 1998;66(1):7-18.

22. Hedges L, Olkin I. Statistical Methods for Meta-Analysis. Orlando, FL: Academic Press; 1985.

23. Cooper H, Hedges L. The Handbook of Research Synthesis. New York, NY: Russell Sage Foundation Press; 1994.

24. Hedges LV. Distribution theory for Glass's estimator of effect size and related estimators. J Educ Behav Stat. 1981;6(2):107-128.

25. Borenstein M, Hedges LV, Higgins JPT, Rothstein HR. Introduction to Meta-Analysis. West Sussex, England: John Wiley \& Sons; 2009.

26. Wersebe H, Sijbrandij M, Cuijpers P. Psychological grouptreatments of social anxiety disorder: a meta-analysis. PLoS One. 2013;8(11):e79034.

27. Hedges LV, Vevea JL. Fixed- and random-effects models in metaanalysis. Psychol Methods. 1998;3(4):486-504.

28. Higgins JP, Thompson SG, Deeks JJ, Altman DG. Measuring inconsistency in meta-analyses. BMJ. 2003;327(7414):557-560.

29. Cuijpers P, Geraedts AS, van Oppen P, Andersson G, Markowitz JC, van Straten A. Interpersonal psychotherapy for depression: a metaanalysis. Am J Psychiatry. 2011;168(6):581-592.

30. Vevea JL, Woods CM. Publication bias in research synthesis: sensitivity analysis using a priori weight functions. Psychol Methods. 2005;10(4):428-443.

31. Cuijpers $P$, van Straten $A$, Andersson $G$, van Oppen P. Psychotherapy for depression in adults: a meta-analysis of comparative outcome studies. J Consult Clin Psychol. 2008;76(6):909-922.

32. Duval S, Tweedie R. Trim and fill: a simple funnel-plot-based method of testing and adjusting for publication bias in metaanalysis. Biometrics. 2000;56(2):455-463.

33. Egger M, Davey Smith G, Schneider M, Minder C. Bias in metaanalysis detected by a simple, graphical test. BMJ. 1997;315(7109): 629-634.

34. Begg CB, Mazumdar M. Operating characteristics of a rank correlation test for publication bias. Biometrics. 1994;50(4):1088-1101.

35. van Ravesteijn $H$, Lucassen $P$, Bor $H$, van Weel C, Speckens A. Mindfulness-based cognitive therapy for patients with medically unexplained symptoms: a randomized controlled trial. Psychother Psychosom. 2013;82(5):299-310.

36. Moritz S, Quan H, Rickhi B, et al. A home study-based spirituality education program decreases emotional distress and increases quality of life-a randomized, controlled trial. Altern Ther Health Med. 2006;12(6):26-35.

37. Plews-Ogan M, Owens JE, Goodman M, Wolfe P, Schorling J. A pilot study evaluating mindfulness-based stress reduction and massage for the management of chronic pain. J Gen Intern Med. 2005;20(12):1136-1138.

38. Kitsumban V, Thapinta D, Sirindharo PB, Anders RL. Effect of cognitive mindfulness practice program on depression among elderly Thai women. Thai J Nurs Res. 2009;13(2):95-107.

39. de Vibe $M$, Moum T. [Training in mindfulness for patients with stress and chronic illness]. Tidsskr Nor Laegeforen. 2006;126(15):1898-1902.

40. Collaboration in primary-care research. Lancet. 2009;373(9659):186.

41. Barrera M Jr, Castro FG, Strycker LA, Toobert DJ. Cultural adaptations of behavioral health interventions: a progress report. J Consult Clin Psychol. 2013;81(2):196-205.

42. Bohlmeijer E, Prenger R, Taal E, Cuijpers P. The effects of mindfulness-based stress reduction therapy on mental health of adults with a chronic medical disease: a meta-analysis. J Psychosom Res. 2010;68(6):539-544.

43. Fournier JC, DeRubeis RJ, Hollon SD, et al. Antidepressant drug effects and depression severity: a patient-level meta-analysis. JAMA. 2010;303(1):47-53. 
44. Shapiro DH Jr. Adverse effects of meditation: a preliminary investigation of long-term meditators. Int J Psychosom. 1992;39(1-4):62-67.

45. Shapiro DH Jr. Overview: clinical and physiological comparison of meditation with other self-control strategies. Am J Psychiatry. $1982 ; 139(3): 267-274$.

46. Perez-de-Albeniz A, Holmes J. Meditation: concepts, effects and uses in therapy. Int J Psychother. 2000;5(1):49-58.

47. Hölzel BK, Lazar SW, Gard T, Schuman-Olivier Z, Vago DR, Ott U. How does mindfulness meditation work? Proposing mechanisms of action from a conceptual and neural perspective. Perspect Psychol Sci. 2011;6(6):537-559.

48. Bowen S, Witkiewitz K, Clifasefi SL, et al. Relative efficacy of mindfulness-based relapse prevention, standard relapse prevention, and treatment as usual for substance use disorders: a randomized clinical trial. JAMA Psychiatry. 2014;71(5):547-556.

49. Craig P, Dieppe P, Macintyre S, Michie S, Nazareth I, Petticrew M. Developing and evaluating complex interventions: the new Medical Research Council guidance. BMJ. 2008;337:a1655.
50. Richards DA. Stepped care: a method to deliver increased access to psychological therapies. Can J Psychiatry. 2012;57(4):210-215.

51. Cavanagh K, Strauss C, Forder L, Jones F. Can mindfulness and acceptance be learnt by self-help? A systematic review and metaanalysis of mindfulness and acceptance-based self-help interventions. Clin Psychol Rev. 2014;34(2):118-129.

52. Kuyken W, Byford S, Byng R, et al. Update to the study protocol for a randomized controlled trial comparing mindfulness-based cognitive therapy with maintenance anti-depressant treatment depressive relapse/recurrence: the PREVENT trial. Trials. 2014;15:217.

53. Sibinga EMS, Perry-Parrish C, Thorpe K, Mika M, Ellen JM. A small mixed-method RCT of mindfulness instruction for urban youth. Explore (NY). 2014;10(3):180-186.

54. Sibinga EMS, Kerrigan D, Stewart M, Johnson K, Magyari T, Ellen JM. Mindfulness-based stress reduction for urban youth. J Altern Complement Med. 2011;17(3):213-218.

\section{Get the Annals of Family Medicine by E-mail}

Make sure you see every new issue

while it's fresh; have the table of

contents sent to you by e-mail for

easy access to articles of interest.

Don't miss important research.

Request the e-mail table of contents at

http://www2.highroadsolution.com/

aafp_annals_preference_center/search.aspx

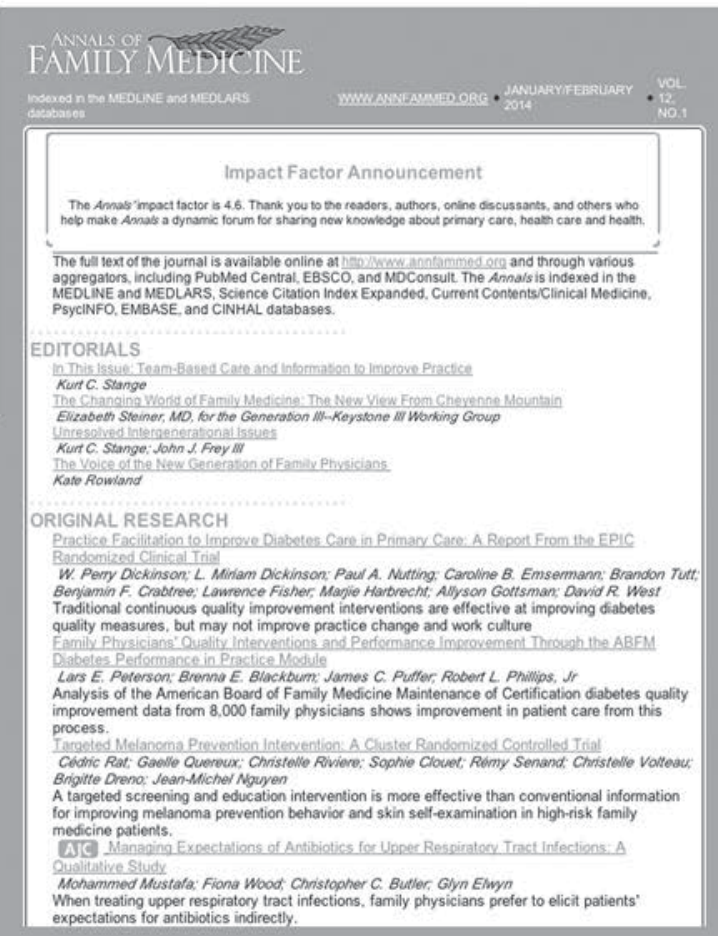

